\title{
Stratum Disjunctum
}

National Cancer Institute

\section{Source}

National Cancer Institute. Stratum Disjunctum. NCI Thesaurus. Code C33626.

The more superficial and permeable sublayer of the stratum corneum. 